\title{
Assessing hotspots within hotspots to conserve biodiversity and support fisheries management
}

\author{
Mara Schmiing*, Hugo Diogo, Ricardo Serrão Santos, Pedro Afonso \\ Centre of IMAR/Department of Oceanography and Fisheries of the University of the Azores, \\ LARSyS - Associated Laboratory, Rua Prof. Doutor Frederico Machado 4, 9901-862 Horta (Azores), Portugal
}

\begin{abstract}
The decline of marine biodiversity can negatively affect the ocean's resilience, goods and services. Consequently, the identification and protection of biodiversity hotspots is often a priority in marine spatial planning. Marine protected areas (MPAs) can also be designated as fisheries management tools to promote sustainable fisheries. However, the integration of fisheries and biodiversity objectives is still the cause of much debate, and challenging to achieve in a simple, straightforward manner. In this study, generalised additive models of (1) various biodiversity indices and (2) an intrinsic vulnerability index of fishes to fishing were applied to produce predictive maps to identify hotspots of biodiversity and fisheries vulnerability, respectively, and combined hotspots of both parameters for shallow coastal fish assemblages surrounding 2 islands in the Azores archipelago, northeast Atlantic Ocean. Individually, hotspots of biodiversity and vulnerability covered up to half of the study area and were quantitatively well represented in the existing MPA network. Although similar levels of representativeness were found for shared hotspots that included both criteria, more importantly, they were substantially smaller than individual hotspots, highlighting the importance of their complete protection to ensure the ecological functioning of multi-objective MPAs. This case study demonstrates a novel use of a fish vulnerability index in support of marine spatial planning. It can be combined with biodiversity patterns that alone may not represent well the areas of higher need for conservation. MPA design and adaptive management processes may use this straightforward approach to identify hotspots within larger areas of high conservation value, especially in data-limited situations that may benefit from predictive modelling.
\end{abstract}

KEY WORDS: Intrinsic vulnerability index $\cdot$ Predictive model $\cdot$ Distribution patterns $\cdot$ Marine protected area $\cdot$ Generalised additive model $\cdot$ GAM $\cdot$ Azores

\section{INTRODUCTION}

The global loss of biodiversity (Sala \& Knowlton 2006, Worm et al. 2006, Staples \& Hermes 2012) and declining or overexploited fish stocks (Pauly et al. 2005, Worm et al. 2009) are 2 driving factors for the increasing number of marine protected areas (MPAs) worldwide (Roberts et al. 2003). Often, MPAs are implemented to serve these, or other, objectives simultaneously (Roberts et al. 2003, Green et al. 2014). The development and management of such multiobjective MPAs is especially challenging (Rice et al.
2012, Green et al. 2014). If successfully implemented and managed, abundances, biomass and diversity of marine organisms can increase inside MPAs (e.g. Friedlander et al. 2003, García-Charton et al. 2004, McCook et al. 2010).

Although debated, biodiversity can be used as a measure of stability of an ecosystem and the goods and services it provides (Chapin et al. 2000, Sala \& Knowlton 2006). For example, diverse systems with the number of individuals evenly distributed among the species are believed to be more stable because of the manifold nature of species interactions (Chapin 
et al. 2000, Worm et al. 2006, Stachowicz et al. 2007). Preserving marine biodiversity is of overall benefit for the ocean's resilience and ecosystem services, including fisheries, recreation and water quality (Worm et al. 2006, Palumbi et al. 2009). This is clearly recognised by the general public that is willing to pay for the protection of marine biodiversity (Ressurreição et al. 2012).

Biodiversity can be measured at the species level, but also as functional, trophic or genetic diversity. Classic diversity indices merely estimate the number of species, such as species richness, or consider the evenness and abundances of species, like the Shannon index (Shannon \& Weaver 1949) or Simpson diversity (Simpson 1949). In the 1990s, Warwick \& Clarke (1995) and Clarke \& Warwick (1998) proposed a set of indices that also consider the phylogenetic structure of assemblages. These indices are believed to be unbiased and independent of sample size (Warwick \& Clarke 1995). The taxonomic diversity $(\Delta)$ and taxonomic distinctness $\left(\Delta^{*}\right)$ are extensions of the Simpson diversity and also consider the average path length connecting 2 organisms through a phylogenetic or Linnean classification (Clarke \& Warwick 1998). $\Delta$ integrates the distribution of abundances amongst species as well as the taxonomic relatedness, and $\Delta^{*}$ can be seen as a pure measure of taxonomic relatedness (Clarke \& Warwick 1998). All of these biodiversity indices have been used in marine science to study the ecological patterns of fish assemblages and to assess (candidate sites of) MPAs (e.g. Roberts et al. 2003, Gladstone 2007, Campbell et al. 2011) .

Many marine organisms are threatened by direct and indirect effects of fishing (e.g. Dulvy et al. 2003, Worm et al. 2009, Madin et al. 2010). One possible attempt to assess the response of fishes to exploitation considers, for example, life history traits (Dulvy et al. 2003, Reynolds et al. 2005). Cheung et al. (2005) used a fuzzy expert system to estimate an index of the intrinsic vulnerability of marine fishes to fishing (IVUL) . This index is based on life history and ecological characteristics of fishes. In general, longlived, large-bodied and slow-growing species with late maturity are the most vulnerable to fishing and show slow recovery from exploitation (Reynolds et al. 2005, Cheung et al. 2007). To assess the total vulnerability or extinction risk of a species, the intrinsic vulnerability could be combined with external factors, such as fishing intensity, habitat degradation or bycatch risk (Cheung et al. 2005).

Spatial management requires spatially explicit information on the distribution of species, assem- blages, habitats and other ecological features (Costello et al. 2010, Sundblad et al. 2011). Yet, such information is often limited to a few sampled locations. To overcome that data scarcity, statistical modelling techniques can be applied and predictive distribution maps can be produced. These can then be used to identify most suitable sites of priority for conservation in a straightforward manner and to assess MPAs (e.g. Cañadas et al. 2005, Sundblad et al. 2011, Schmiing et al. 2013).

Here we propose a simple and efficient approach to identify candidate sites for networks of multiobjective MPAs that serve both conservation of biodiversity and fisheries management objectives. Spatially explicit models are used to characterise patterns of different biodiversity indices and an intrinsic vulnerability index of coastal fishes to fishing in relation to bathymetry, substrate and oceanographic forces. Predictive distribution maps of these indices are evaluated, individually and combined. The presented approach is believed to support MPA assessment and, for example, adaptive management processes, especially in data-limited situations.

\section{MATERIALS AND METHODS}

\section{Study area}

Coastal habitats were studied, from the surface down to $40 \mathrm{~m}$ depth, of Faial and western Pico Islands in the Azores archipelago, northeast Atlantic Ocean (Fig. 1). Island shelves are limited and quickly drop to several hundred metres depth, except in the channel that separates the 2 islands that has a minimum width of $6 \mathrm{~km}$ and a maximum depth of $190 \mathrm{~m}$ (Fig. 1). In addition, coastal fish assemblages experience a high degree of isolation from other populations, making them particularly sensitive to disturbances (Santos et al. 1995). Coastal habitats are diverse and include bedrock reefs, boulder fields, cliffs, submerged cones and enclosed sandy bays, that are subject to a variety of hydrodynamic conditions (Santos et al. 1995). More than half of the study area $\left(59 \%, 34 \mathrm{~km}^{2}\right)$ is composed of rocky substrate (Tempera et al. 2012). Each island has a designated 'Island Natural Park' (INP) under national legislation, including terrestrial and marine sites that are classified as categories Ia or VI under the International Union for Conservation of Nature (IUCN) Protected Areas system (Dudley 2008). Six marine sites of the Faial-INP and Pico-INP are partly inside the study area (Fig. 1 -note that not all sites are visible at this 


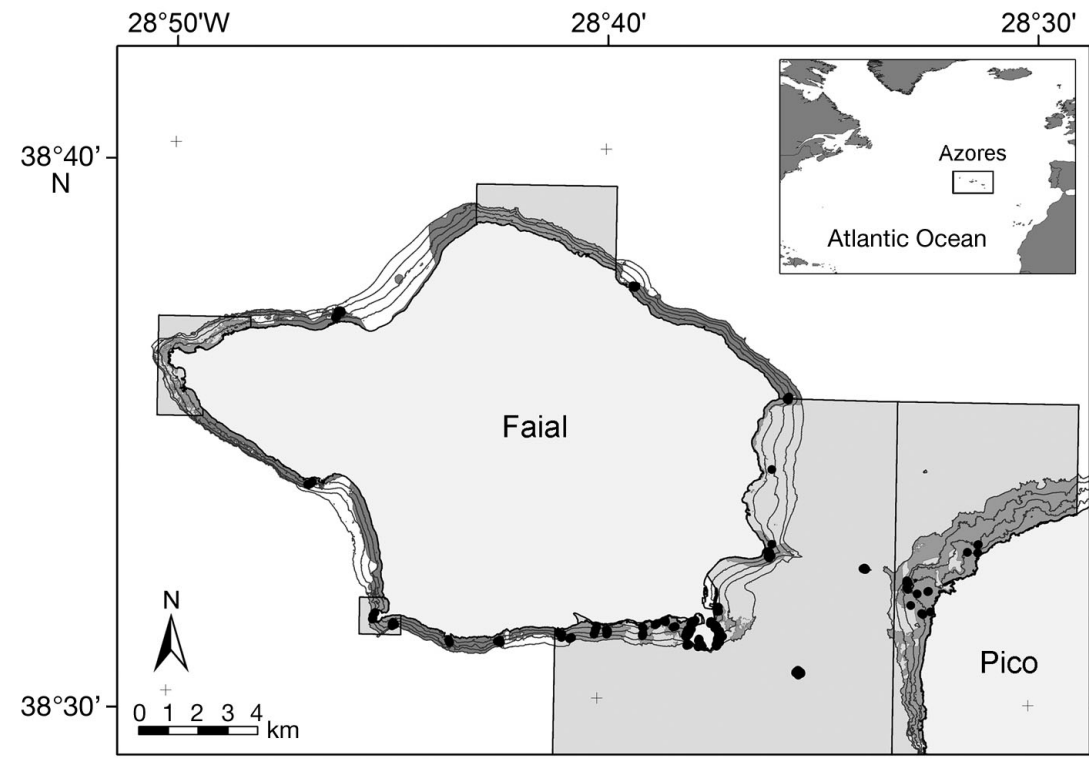

Fig. 1. Study area. Black dots indicate the location of 462 underwater visual transects (dots of neighbouring transects overlap) used to study the coastal fish assemblage of 2 islands (light grey) in the Azores archipelago (northeast Atlantic Ocean). Dark grey shaded areas: rocky bottom mapped down to the $40 \mathrm{~m}$ isobath. Also shown are $10 \mathrm{~m}$ isobaths down to $40 \mathrm{~m}$ and the existing marine protected areas (mid-grey shaded boxes) main habitat type: rock or sediment). Typically, 2 transects (minimum 1, maximum 7) that did not overlap or represent the same strata were sampled during 1 dive. In total, 462 transects were sampled from June 1997 to October 2004. Juveniles were not considered in this study because they are not efficiently counted during UVCs. All transects were georeferenced and projected in a geographic information system (GIS, ArcGIS 9.3@ESRI). A detailed description is given in Schmiing et al. (2013).

\section{Fish community parameters}

Species were grouped according to their trophic level (Harmelin-Vivien et al. 2001), main habitat type (Claudet et al. 2010) and commercial use (Morato et al. 2001, and see www.lotacor.pt/). Three classic biodiversity indices were calculated based on all sightings along 1 transect: species richness $(S$, the number of scale) and encompass about $60 \%$ of the area down to the $40 \mathrm{~m}$ isobath. The 2 main fisheries are commercial artisanal, using gillnets, traps and various forms of hooks and lines (Morato et al. 2001), and recreational fisheries, including spear fishing, shore angling and boat fishing (Diogo \& Pereira 2014). Depending on the fishing type, certain regulations may apply inside INPs. Recent studies suggest that recreational fishing activities have a considerable impact on coastal fish assemblages, as they were estimated to land about half of the commercial artisanal landings (Diogo \& Pereira 2014).

\section{Fish counts}

Shallow coastal fish assemblages (down to $40 \mathrm{~m}$ ) were investigated by SCUBA divers with underwater visual censuses (UVCs) using a standard transect belt method (Brock 1954) and a stratified random sampling design. Fish species were identified to the lowest possible taxon and counted along $50 \times 5 \mathrm{~m}$ transects, whereby 1 diver counted all mobile fish (e.g. Sparidae, Labridae, Scaridae, Carangidae) along the transect mid-line and a second diver followed behind counting cryptic species that typically hide under crevices and boulders (e.g. Muraenidae, dusky groupers). Transects were parallel to the coast to stay within the same strata (i.e. depth strata: each $10 \mathrm{~m}$, species), Shannon index $\left(H^{\prime}\right)$ and Simpson diversity $(1-D)$. In addition, the taxonomic diversity $(\Delta)$ and taxonomic distinctness $\left(\Delta^{*}\right)$ that consider the taxonomic relatedness were assessed. Two (or more) individuals must be from different species for the calculation of $\Delta^{*}$ (Warwick \& Clarke 1995). Indices were calculated with the vegan package (version 2.0-5, Oksanen et al. 2012) in R (version 2.14.2, R Development Core Team 2012) using an equal step length between successive levels in the taxonomic hierarchy (species, genus, family, order, class) in the distance matrix. If only 1 species or a single individual of 1 species, respectively, was sighted in a transect, $\Delta$ or $\Delta^{*}$ could not be estimated and these samples were excluded from modelling ( $\Delta=3, \Delta^{*}=11$ transects).

The IVUL that rates the vulnerability of fishes to fishing is based on life history and ecological characteristics, namely maximum body length, age at first maturity, von Bertalanffy growth parameters, natural mortality rate, maximum age, geographic range, annual fecundity and aggregation behaviour (Cheung et al. 2005). IVUL ranges from 1 to 100, considering values from 1 to 30 as low, from 30 to 50 as moderate, from 50 to 70 as high and from 70 to 100 as very high and most vulnerable (Cheung et al. 2005). Fuzzy set theory allows gradation of membership. For example, a species with an IVUL of 70 has a partial membership to both the category 'high' and 'very 
high' (Cheung et al. 2005). IVULs of each species were obtained from Cheung et al. (2007) or FishBase (Froese \& Pauly 2013). The average IVUL of each transect was calculated from the arithmetic mean of the IVUL of fish taxa weighted by their abundance (i.e. counts, adapted from Cheung et al. 2007). A summary of all species and parameters is provided in Table S1 in the Supplement (www.int-res.com/ articles/suppl/m513p187_suppl.pdf).

\section{Predictive models}

The relationship of the biodiversity indices to available environmental variables (see Tempera et al. 2012 and Schmiing et al. 2013 for a detailed description) was non-linear and was therefore analysed with generalised additive models (GAMs) using the mgcv package (version 1.5-5, Wood 2006) in the software R. A thorough data exploration (Zuur et al. 2007), systematic model formulation, selection and validation were applied to avoid possible overfitting of the data. Depending on the response variable, different probability distributions and link functions were used (Table 1). Predictive models were built with data from the main sampling period ('summer data': June to November, 354 transects, Kruskal-Wallis rank sum test revealed no significant differences between these months) to account for an unequal temporal/ seasonal sampling effort (Schmiing et al. 2013). Following results from data exploration, which identified and excluded correlated variables, 5 out of 11 environmental variables were used as the initial set of explanatory variables (see Table 2 in Schmiing et al. 2013): (1) depth (mean transect depth measured in situ), (2) slope (mean seafloor steepness estimated in ArcGIS from a bathymetric grid), (3) distance to sediment (mean distance to the nearest soft bottom, estimated in ArcGIS), (4) exposure to current (relative exposure, upscaled, from an oceanographic model) and (5) exposure to swell (relative exposure, upscaled, GIS-based fetch analysis) (see Tempera 2008, Tempera et al. 2012). All variables were available as raster layers in a GIS (5 m grid). Exposure to current was square-root transformed and distance to sediment was log transformed (base 10, adding the constant 1 because of 0 values). A detailed description of all environmental variables and the data exploration is given by Schmiing et al. (2013). The same approach was used to model the IVUL of commercial species, applying a gamma error distribution.

Starting with the full model, stepwise backwards selection with minimisation of the Akaike informa-

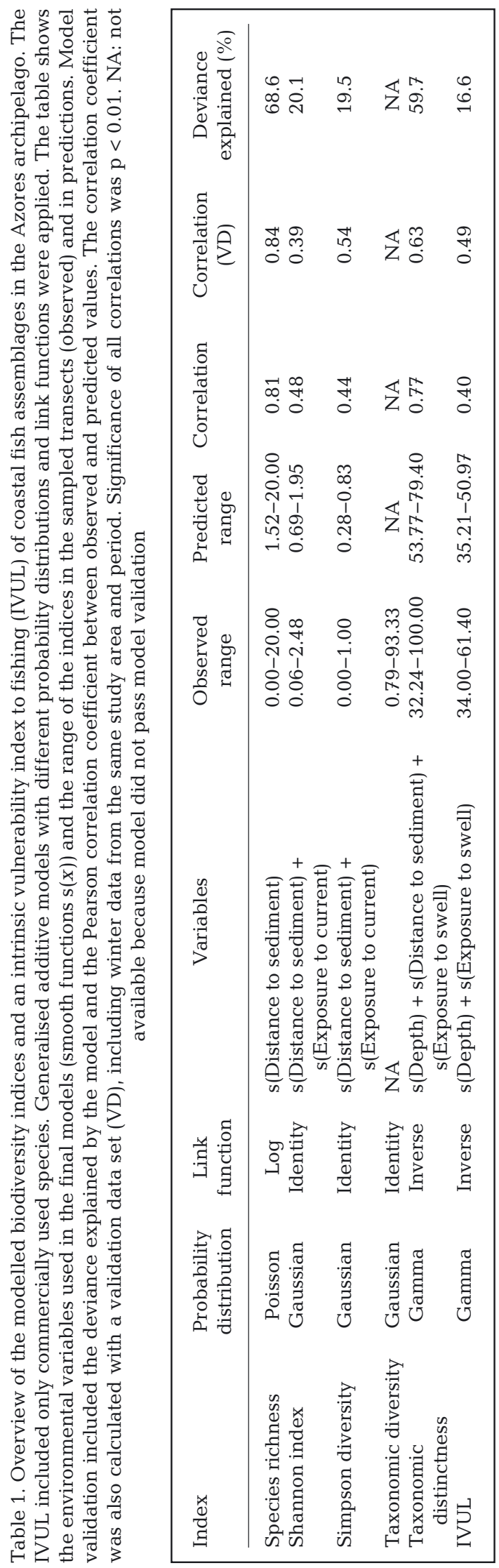


tion criterion was conducted. In addition, hypothesis testing (chi-squared test) was used in the last step, and only smoothers that did not continuously include 0 in the confidence interval were accepted (Wood \& Augustin 2002). Final models were validated by graphical analyses of the leverage and residuals, and approved if no outliers, patterns, heterogeneity, spatial or temporal dependence was present (Zuur et al. 2007). Residuals were plotted versus (1) each explanatory variable (including the 6 variables omitted during data exploration, see above), (2) the spatial coordinates of the transects, and (3) the sampling years and months. In addition, Pearson's correlation coefficient between predicted and observed values was calculated. The correlation analysis was repeated with a validation data set ('winter data': December to May, 108 transects). These data are from the same study area and sampling period and were previously set aside from the model building data set (see Schmiing et al. 2013 for more details). Final models that passed validation were used to produce spatial predictions on a $5 \mathrm{~m}$ grid over the entire study area, down to the $40 \mathrm{~m}$ isobath.

\section{Spatial analyses and identification of hotspots}

Predictive spatial patterns of biodiversity and vulnerability to fishing were analysed in relation to the existing MPA network, and potential priority sites for conservation were identified. For this purpose, 'hotspots' were identified as sites where the IVUL was $\geq 50$ (Cheung et al. 2005) and biodiversity indices were in the highest of 3 natural break categories (Jenks optimisation, Jenks \& Caspall 1971). The choice of the latter threshold was based on the frequency distributions of predictions and defined to be at the lower boundary of the last peak to avoid possible under-representation of high values (see Fig. S1 in the Supplement). Using the predictive maps, total hotspot size and the percentage that fell inside the existing MPAs were calculated in ArcGIS. In addition, maps were overlaid to identify sites with combined elevated IVUL and biodiversity $\left(S\right.$ and $\left.H^{\prime}\right)$ that are considered to be of highest conservation value (i.e. hotspots within hotspots). Simpson diversity (1 $D$ ) was not used for this exercise because the resulting predictive model and map was very similar to the model of $H^{\prime}$. Instead, the focus was on $H^{\prime}$ because of its wide application in ecology, and because it is more sensitive to rare species and recommended for ecological frameworks that do not focus on dominant or single species (Nagendra 2002). Similarly, no shared hotspots of IVUL and $\Delta^{*}$ were identified because predictions of $\Delta^{*}$ were biased (i.e. only 1 unique value was above the hotspot threshold).

\section{RESULTS}

\section{Composition of fish assemblages}

In total, we identified 57 taxa, including 3 species of rays and a single shark, representing 50 genera and 28 families (Table S1 in the Supplement). The most diverse families were Labridae (8 species), Sparidae $(7$ species) and Carangidae (6 species). Sightings were dominated by 3 species (Diplodus sargus, Thalassoma pavo, Coris julis) that were present in $>75 \%$ of the censuses, reaching a maximum observation frequency of $84 \%$. Another 8 species occurred in $>50 \%$ of the censuses (decreasing order of frequency of occurrence: Serranus atricauda, Chromis limbata, Sarpa salpa, Sphoeroides marmoratus, Boops boops, Mullus surmuletus, Abudefduf luridus, Sparisoma cretense). Half of the species (29) were present in $<5 \%$ of the censuses, of which 15 species were observed with a frequency of $<1 \%$ ( $<5$ sightings; Table S1). The majority of observed species were representatives of the benthic habitat (35 benthic, 15 bentho-pelagic species) and carnivorous (38 species). Herbivorous taxa were the least represented (4 species). Most species had a moderate to high IVUL, and 3 species had a very high vulnerability index ( $\geq 70$, Table S1). The average IVUL of all species from all transects was 43.9. The average IVUL of commercial fishes in summer UVCs (45.1) was similar to the median (43.1) and average predicted value (45.5). Five species are considered as threatened in the IUCN Red List of Threatened Species (IUCN 2013): Epinephelus marginatus, Mycteroperca fusca and Pagrus pagrus are listed as Endangered, and Bodianus scrofa and Galeorhinus galeus as Vulnerable.

\section{Spatial patterns of fish biodiversity}

Predictive models of $S, H^{\prime}, 1-D$ and $\Delta^{*}$ passed model validation (Table 1): no residual patterns, heterogeneity, spatial or temporal dependence or outliers were detected in the final models. It was not possible to produce a sound model for $\Delta$ because residual analysis revealed the violation of underlying statistical assumptions (i.e. patterns and heterogene- 
ity). The deviance explained ranged from approximately $20 \%\left(H^{\prime}, 1-D\right)$ to $>59 \%\left(\Delta^{*}, S\right)$. The highest correlation between predicted and observed values, for both the model building and validation data set, was found for the model of $S$. Resulting GAM smoothers are provided in Fig. S2 in the Supplement. All 4 biodiversity indices were significantly influenced by distance to sediment, where $\Delta^{*}$ was highest above sediment and the other indices at a distance of $\geq \sim 10 \mathrm{~m}$ (Fig. S2). Similarly, exposure to oceanographic forces (current or swell) significantly influenced most biodiversity indices, which generally decreased with increasing exposure. Slope was never significant and depth was only significant for patterns of $S$.

Predictive maps were produced for the 4 models that passed model validation. They illustrate the spatial heterogeneity and reflect the strong influence of the main habitat type (Fig. 2). Highest values for all classic biodiversity indices were predicted for rocky habitats around Faial and Pico Islands. In contrast, $\Delta^{*}$ was highest above sediment, and the predictive map mainly depicted the 2 extreme ends of the predicted range (Fig. 2, Fig. S1). Species richness increased with depth (Fig. S2). The predictive map of $1-D$ is shown in Fig. S3 in the Supplement. It was visually similar to $H^{\prime}$ because model results (i.e. smoother estimates, Fig. S2) were nearly the same for both indices. The map-based spatial assessment showed that, depending on the index, high-biodiversity sites covered one-third $(S)$ to about half $\left(H^{\prime}\right)$ of the study area (Table 2). Of these hotspots, 54 to $68 \%$ were represented in the existing MPA network.

\section{Spatial patterns of vulnerability to fishing}

Depth and exposure to swell significantly influenced spatial patterns of the IVUL of commercial fishes (Fig. S2). Overall, it decreased with exposure and increased with depth. The final model explained only $16.6 \%$ of the deviance but performed well in validation (Table 1) and did not violate any underlying statistical assumption. Thus, it was used to pro-
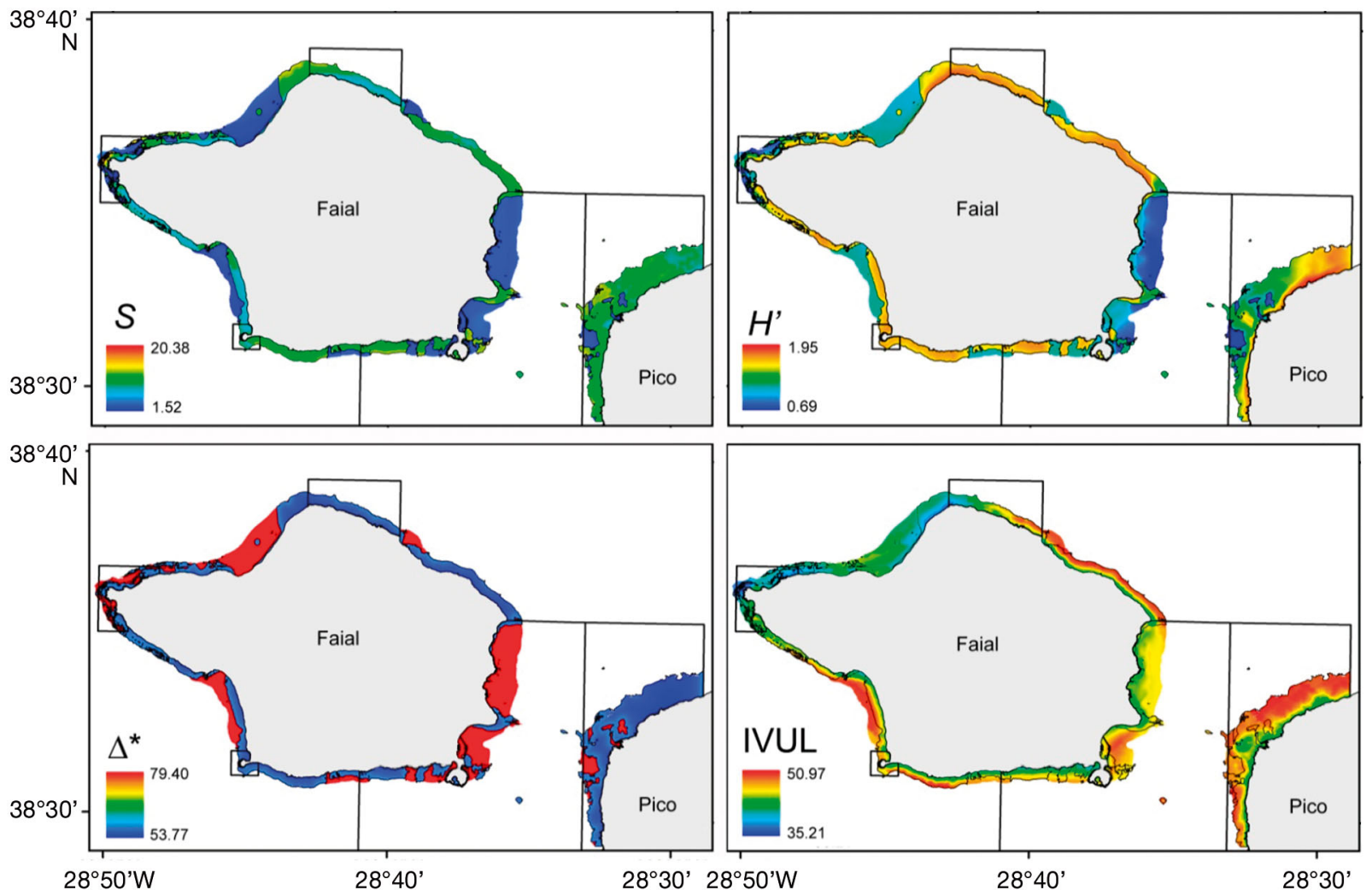

Fig. 2. Predicted spatial distribution of species richness $(S)$, Shannon index $\left(H^{\prime}\right)$, taxonomic distinctness $\left(\Delta^{*}\right)$ and intrinsic vulnerability index (IVUL) of coastal fishes (subtidal habitat down to $40 \mathrm{~m}$ depth), in relation to the boundaries of the existing marine protected area network (black rectangles) in 2 islands of the Azores archipelago. The IVUL includes only commercially used species. The outline of the rocky substrate is shown as a black contour (see also Fig. 1). Note the different scales for the indices 
Table 2. Identification of biodiversity and vulnerability hotspots around Faial and Pico Islands, Azores archipelago. Natural breaks (Jenks optimisation) of 4 biodiversity indices were used to define the most diverse sites (within the highest of 3 classes), and an intrinsic vulnerability index to fishing (IVUL) $\geq 50$ (Cheung et al. 2005) was used as the threshold to define the most vulnerable sites. The percentage coverage in the study area and in the existing marine protected area (MPA) network is indicated. For comparison, about $60 \%$ $\left(35 \mathrm{~km}^{2}\right)$ of the study area was inside the MPAs

\begin{tabular}{|lccc|}
\hline Index & Threshold & $\begin{array}{c}\% \text { of } \\
\text { study area }\end{array}$ & $\begin{array}{c}\% \\
\text { protected }\end{array}$ \\
\hline Species richness & $\geq 10.10$ & 33.2 & 68.4 \\
Shannon index & $\geq 1.39$ & 47.3 & 55.5 \\
Simpson diversity & $\geq 0.63$ & 44.0 & 53.9 \\
Taxonomic distinctness & $\geq 63.92$ & 41.6 & 59.5 \\
IVUL & $\geq 50.00$ & 11.3 & 55.7 \\
IVUL + Species richness & $\geq 50.00, \geq 10.10$ & 4.3 & 71.0 \\
IVUL + Shannon index & $\geq 50.00, \geq 1.39$ & 5.8 & 63.2 \\
\hline
\end{tabular}

duce a predictive map of the IVUL. Maximum predicted values (51.0) were less than the maximum observed value of commercial fish assemblages of one transect in summer (61.4, Table 1). Map-based analyses showed that areas with a high IVUL covered $11 \%$ of the study area (Table 2, Fig. 2). These areas were smaller than biodiversity hotspots but representativeness in the existing MPAs was comparable $(56 \%)$.

High IVUL sites coincided with high biodiversity sites in $<10 \%$ of the study area, whereas the spatial overlap of shared hotspots that considered either $S$ or $H^{\prime}$ was high $(>50 \%)$. About two-thirds $(63-71 \%)$ of these hotspots fell inside the existing MPA network, mainly in the channel between Faial and the Pico Islands (Table 2, Fig. 3).

\section{DISCUSSION}

\section{Composition of fish assemblages}

The coastal fish assemblage, as expected, had a high proportion of infrequently observed species and only few species dominated. The community structure was comparable to other studies in the Macaronesian region that also used visual censuses, such as the Azores (Harmelin-Vivien et al. 2001, Bertoncini et al. 2010), Madeira Island (Ribeiro et al. 2005) and the Canary Islands (Falcón et al. 1996). In general, sparids, labrids and carangids were the most diverse groups, and carnivores dominated the assemblages, whereas herbivores and omnivores were only present at low percentages. Assemblages in this study have about half of the species in common with assemblages in Madeira (Ribeiro et al. 2005) and about two-thirds with those in the Canaries (Falcón et al. 1996). In general, the ichthyofaunas of these Macaronesian islands are more similar to each other than to that of the Portuguese mainland and the Mediterranean (Santos et al. 1995, HarmelinVivien et al. 2001), although some species overlap. For example, fish assemblages described in Spain (García-Charton et al. 2004) and continental Portugal (Henriques et al. 2013) had about one-third of the species in common with our study. However, the direct comparison between species counts of different studies is difficult because results may be influenced by the census design (e.g. transect length, depth and
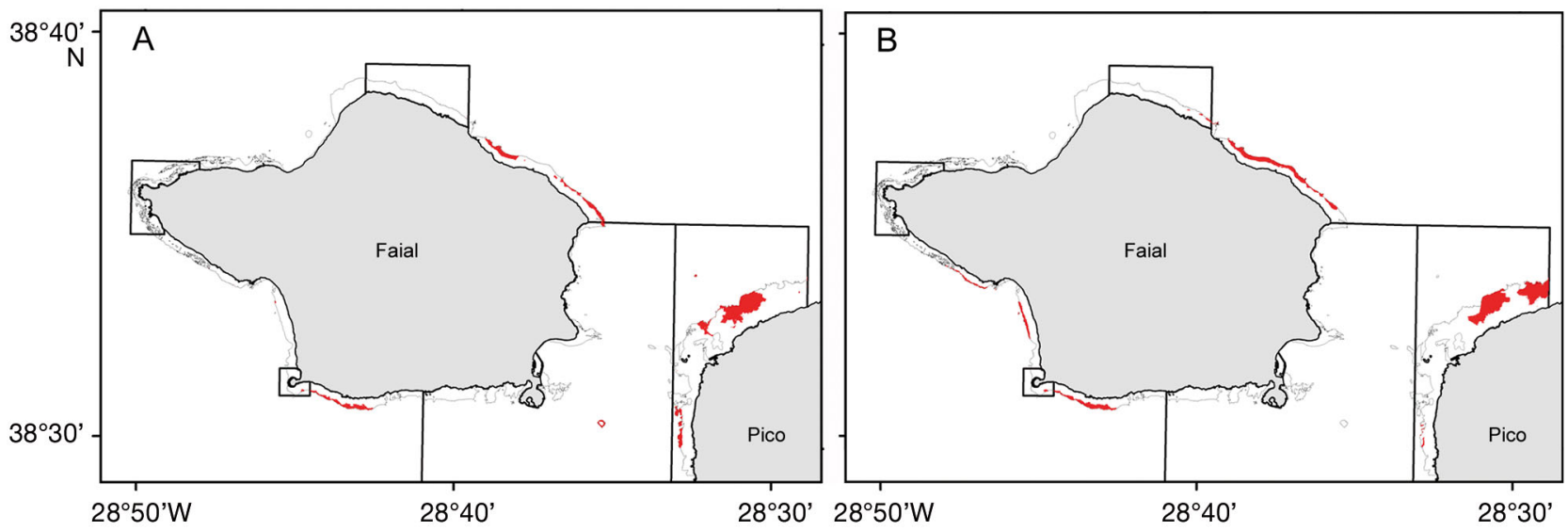

Fig. 3. Combined hotspots (red) of high vulnerability of commercial fishes to fishing and (A) species richness or (B) Shannon index in 2 islands of the Azores archipelago. The boundaries of the existing marine protected area network (black rectangles) and rocky substrate down to $40 \mathrm{~m}$ (grey line, see also Fig. 1) are shown 
sampling season; Harmelin-Vivien et al. 2001, Kulbicki et al. 2010, Henriques et al. 2013).

The average observed and predicted IVUL of commercial fishes was similar to the average vulnerability of worldwide exploited coral reef-associated fishes (about 48 out of 100) and coastal species (about 46, Cheung et al. 2007). Cheung et al. (2007) identified that the average vulnerability of commercially exploited fish assemblages declined due to reduced catches of large-bodied, long-lived, late-maturing and thus more vulnerable species, especially in coastal regions. These are depleted more rapidly (Lloret et al. 2008) and consequently, the community structure shifts and proportional catches of less vulnerable species increase. Azorean communities may already be showing this influence of fishing (Diogo \& Pereira 2013). Alternatively, the moderate average IVUL may be attributed to the natural composition of coastal fish communities which is dominated by small-bodied, fast-growing and highly reproductive species (e.g. Labridae, Scaridae; Harmelin-Vivien et al. 2001, Bertoncini et al. 2010, this study). Unfortunately, there is no objective way to distinguish between these 2 hypotheses in our study. The MPAs are not fully implemented and thus it is not possible, for example, to compare protected with unprotected assemblages. More studies are needed to analyse the effects of fishing, as the results would certainly influence management strategies.

\section{Performance of predictive distribution models}

Spatially explicit distribution models were implemented for a set of biodiversity indices of fish assemblages and the IVUL of commercial fishes. Model validation revealed strengths and weaknesses of the models' performance. For example, the model of $H^{\prime}$ and $1-D$ had a low deviance explained and a comparatively low correlation between predicted and observed values, indicating that one or more important environmental variables that influence the patterns of these indices are missing. The models could not be improved by inclusion of previously omitted variables (i.e. during data exploration) or by considering, for instance, variable interactions. However, included variables were highly significant, and should not lose their importance, even if other variables are identified and used in future models. Nevertheless, all other model validation steps (i.e. residual plots) were good. Ideally, all presented models should also be tested against spatially independent data and predicted hotspots should be validated in situ. The resulting predictive map of $\Delta^{*}$ only displays the extreme ends of the predicted scale and misses fine-scale differences between habitats, although the model explained $60 \%$ of the deviance. It merely differentiates between the main habitat types, viz. sediment and rock, whereas the entire sediment is characterised by the same value. Fewer transects were sampled above sediment, but model results did not differ when soft-bottom species were excluded to account for that bias. Similarly to the models of $H^{\prime}$ and $1-D$, additional environmental information may further distinguish patterns of $\Delta^{*}$.

Analogous to the models of $H^{\prime}$ and $1-D_{\text {, the }}$ explained deviance of the IVUL model was low, although it otherwise performed well during validation. Its weakness lies in predicting vulnerability at the lower and upper end of the index range. However, experimental GAMs including one or more of the environmental variables that were excluded during data exploration did not improve the fit.

\section{Key environmental variables}

All biodiversity indices, except $\Delta^{*}$, increased for the first $10 \mathrm{~m}$ of rocky bottom and subsequently remained the same. On the one hand, rocky areas are structurally more complex and offer a wider range of habitats and refuges than sediment, resulting in higher fish biodiversity (e.g. García-Charton et al. 2004, Ribeiro et al. 2005, Pittman et al. 2007). On the other hand, distance to sediment does not merely distinguish between hard and soft bottom but also shows edge effects between both habitat types (Schmiing et al. 2013), as shown by small peaks at about $10 \mathrm{~m}$ distance to sediment, i.e. the transition zone. Such zones are known to support higher biodiversity, fish abundance and biomass (Friedlander \& Parrish 1998, Pittman et al. 2007) and, consequently, should also be considered in marine spatial management.

Contrary to all other biodiversity indices, $\Delta^{*}$ decreased with increasing distance to sediment. This pattern is probably driven by a few species of distant taxonomic groups (e.g. Bothus podas, Mullus surmuletus, rays) that were mainly sighted on sandy bottom or at the rock-sand interface. For example, the highest observed $\Delta^{*}(\geq 80)$ was observed for transects with a maximum of 4 species above sediment. Although $\Delta^{*}$ was not used for further analyses in this study, biodiversity indices based on taxonomic distinctness have been successfully used to analyse fish assemblages. For example, Campbell et al. (2011) studied deep-water fish communities that included 
96 species, representing 75 genera and 39 families. However, the study area and depth range was much larger, indicating that $\Delta$ and $\Delta^{*}$ might perform better if no extreme spatial and bathymetric limitations are given. Thus, future studies in the Azores and comparable regions may need to consider the entire shelf habitat to effectively analyse patterns of taxonomic diversity.

Concordant to other studies, the present work highlights the influence of exposure on coastal fish assemblages. Similarly to abundance or biomass, biodiversity decreased with increasing degree of exposure (Friedlander et al. 2003, Krajewski \& Floeter 2011, this study). Depth was only significant in explaining assemblage richness but did not influence other biodiversity measures. Its importance would most probably change if habitats below $40 \mathrm{~m}$ depth would be included, for instance the shelf break. Major changes in the assemblage composition are known to occur along that depth gradient (Menezes et al. 2006). The use of baited remote underwater video systems is a non-invasive method to study fish assemblages at greater depths (Zintzen et al. 2012). This method is currently being tested in our study region and may enable expanding predictive modelling to deeper habitats in the future.

The IVUL model of commercial fishes revealed the significance of depth. Deeper assemblages were potentially more vulnerable to fisheries than shallower ones, in agreement with studies including marine fishes worldwide (Cheung et al. 2007). Largebodied, slow-growing, late-maturing and thus more vulnerable species like Epinephelus marginatus, Muraena helena and Mycteroperca fusca (Cheung et al. 2007, Bustos et al. 2009, Froese \& Pauly 2013) have a wide depth range, also occur deeper than $40 \mathrm{~m}$ (Menezes et al. 2006, Bustos et al. 2009) and probably influence the observed pattern. On the other hand, small- and medium-bodied, fast-growing species with high reproductive potential that have a low to moderate vulnerability index (Cheung et al. 2005), such as Balistes capriscus, Diplodus sargus and Sparisoma cretense, are more abundant in shallow habitats (Harmelin-Vivien et al. 2001, Bertoncini et al. 2010, Schmiing et al. 2013). Many of these species are herbivores or omnivores, and their increased presence in shallow areas can be explained by environmental characteristics (Schmiing et al. 2013). However, dominance of lower trophic guilds can also be indicative of the removal of higher trophic levels (i.e. carnivores) due to selective fishing pressure (Pauly et al. 2005, Lloret et al. 2008, Diogo \& Pereira 2013). Intense fisheries may change the mean trophic level and also the average intrinsic vulnerability of shallow assemblages (Lloret et al. 2008). Further studies are needed to objectively identify whether observed patterns are fisheries related or 'natural' (see 'Discussion: Comparison of fish assemblages').

\section{Implications for marine conservation planning}

The ocean's resilience and capacity to supply human populations with food may decrease due to a decline of marine biodiversity (Sala \& Knowlton 2006, Worm et al. 2006). Consequently, the mapping of biodiversity is very important, and the identification of biodiversity hotspots is often demanded in conservation planning (e.g. Myers et al. 2000, Palumbi et al. 2009). A set of biodiversity indices was modelled in the present study. The merits and drawbacks of these indices are extensively discussed and no consensus has been reached which of them is the most suitable to assess biodiversity (Magurran 2004). Our results indicate that the performance of predictive models of classic and taxonomic biodiversity indices varies, as do the location and size of biodiversity hotspots. This emphasizes the need to clearly formulate the biological/ecological objectives of an MPA (Campbell et al. 2011). For example, species richness may be easy to estimate and interpret, but it considers all species of a community equally and does not weigh them, for instance, according to their relative abundance. On the other hand, the Shannon index is sensitive to changes in rare species, whereas the Simpson diversity is weighted towards the most abundant species and is sensitive to changes in common species (Nagendra 2002, Magurran 2004). These classic biodiversity indices are sensitive to sample size, and may indicate equal biodiversity of assemblages with the same number of species that, in fact, are different (Warwick \& Clarke 1995, Magurran 2004). For example, an assemblage consisting of distantly related species (e.g. different families or phyla) is more diverse than an assemblage composed of similar taxa (e.g. species of the same family). Taxonomic biodiversity indices overcome this weakness by considering the average evolutionary distance between species (Warwick \& Clarke 1995, Clarke \& Warwick 1998). However, they were not as efficient as the other indices in this case study. These findings should be verified on a larger scale before generalising conclusions. However, different biodiversity indices provide complementary information about the community structure and, consequently, conservation planning may benefit from a combined use of 
several indices (Sala \& Knowlton 2006, Campbell et al. 2011).

Predicting patterns of biodiversity indices may be a valuable addition to the utilisation of individual species distribution maps. Indices can integrate a variety of taxa simultaneously and, clearly, it would be more effort to model the same set of species individually and combine resulting distribution maps to assess the biodiversity within an ecosystem. Future work may compare results of both approaches and assess their strengths and limitations. Nevertheless, spatial distribution patterns of single species may support the designation of appropriate management plans (e.g. Cañadas et al. 2005, Bellido et al. 2008, Schmiing et al. 2013). For example, threatened or highly mobile species may benefit from the protection of previously mapped, ecologically important areas/essential habitats (e.g. Bellido et al. 2008, Game et al. 2009, Santora \& Veit 2013). Individual species distribution maps were not integrated in the approach presented here because no sound models could be established for the 5 threatened species. Ultimately, however, the conservation objective will guide the choice of using single species and/or biodiversity indices. Additionally, the cultural valuation of different taxa will influence the selection of target species, if societal preferences are also considered in conservation planning (Ressurreição et al. 2012).

The IVUL is a straightforward method to study the sensitivity of fish assemblages to exploitation. It can be used to support site selection of fisheries-related MPAs. Spatially explicit analyses were based on the mean of the IVUL of commercial species, weighted by their abundance. Excluding non-commercial species, which typically had the lowest vulnerability, reduces the risk of calculating a non-representative IVUL of the assemblage. Alternatively, vulnerability categories defined by Cheung et al. (2005) may be used to weigh species differently and, for example, give more weight to the most vulnerable species. IVUL increases with depth, obviously highlighting the importance of protecting deeper habitats. Yet, shallow-water assemblages still may need to receive special attention for protection, especially (1) when coastal shelf habitats are limited in size and isolated from others by deep waters, such as in oceanic islands (Santos et al. 1995), and (2) considering the high cumulative impact of human activities in coastal ecosystems (Halpern et al. 2008). These habitats hold important nursery grounds (Nash et al. 1993), recruitment sites (Afonso et al. 2008) and adult habitats (Afonso et al. 2011). If pressure on these already constrained habitats is increased by fishing, species have no alternative habitat for recovery. Consequently, a lower vulnerability index at shallower depths does not automatically imply a better recovery of fish assemblages from fishing, and a systematic management of this habitat and its resources is advisable. Future studies may also integrate distribution patterns of juvenile fishes to further improve management. Similarly, other measures, such as IUCN categories (IUCN 2013) or the NatureServe climate change vulnerability index (Young et al. 2010) might be used to extend the presented approach to other taxa and habitats.

MPAs that serve multiple objectives are increasingly implemented, for example to benefit biodiversity conservation and fisheries simultaneously (e.g. Roberts et al. 2003, Rice et al. 2012, Green et al. 2014). Accordingly, biodiversity patterns alone may not represent well the areas of higher need for conservation. Integrating the intrinsic vulnerability to fishing in spatial planning may result in a more precise identification of priority sites. Consequently, areas with a high IVUL were overlaid with high biodiversity sites to identify multi-objective hotspots. Such shared hotspots were substantially smaller than biodiversity or fishing vulnerability hotspots separately, further highlighting their need for conservation. All hotspots (i.e. individual and shared) were well represented in the existing MPA network, and were above commonly recommended targets for MPA establishment (e.g. $30 \%$ of each marine biome or habitat, World Parks Congress 2003). On the other hand, a comparable amount of the study area (60\%) is already integrated in the existing MPA network, relativising these numbers. However, the upper range of promoted targets should be regarded as a minimum (Gladstone 2007), and, more importantly, protection of complete hotspots may be advisable to ensure best ecological functioning and delivery of marine goods and services. Protected hotspots were mainly in the channel between the islands. Around Faial, however, they largely fell outside the existing MPAs. These hotspots should receive particular attention in future decision making processes. Adaptive management processes, for example, may use results of this study to adjust site selection of the existing MPA network.

Instead of targeting high-diversity sites as was the strategy of this study, alternatively, low-diversity sites may be analysed. These may have an even greater need for protection if the emphasis of an MPA is on ecosystem functioning (Roberts et al. 2003). Such sites may be less variable, resilient and resistant against environmental changes, including 
anthropogenic influences (Chapin et al. 2000, Worm et al. 2006, Stachowicz et al. 2007) and, arguably, may lead to more sensitive assemblages. This applies particularly when assemblages also exhibit a high vulnerability to fishing. However, in addition to fish biodiversity and vulnerability, other spatial information may influence the selection of priority sites for conservation as well, such as human impacts (Roberts et al. 2003, Halpern et al. 2008, Staples \& Hermes 2012) or the importance of an area for tourism (Dudley 2008, McCook et al. 2010).

Certainly, the presented classification and identification of hotspots may be further adapted. The study area was considered as 'a single unit'. Yet, it may be reasonable to identify hotspots in different biomes and/or biotopes to facilitate choosing a range of species with different ecological functioning and, vice versa, to reduce the risk of selecting redundant sets of species. In the Azores, stratification into biomes would be vital, for instance, if deep-sea habitats and seamounts were to be integrated in the analysis. Furthermore, other criteria can be used to define hotspot thresholds. Hotspots, for example, may contain a certain percentage of the target species or grid cells with the highest values (Myers et al. 2000) or sites with values $>1$ SD above the mean (Santora \& Veit 2013). The choice of a criterion ultimately depends on the respective case study, and it will always have some degree of subjectivity (Cayuela et al. 2011).

This study demonstrates the utility of predicting the distribution of biodiversity indices and vulnerability of marine fishes to fishing in the context of marine conservation planning. Predictive models help to improve the knowledge about biological and ecological spatial patterns, if modelling techniques are thoroughly implemented and are in concordance with statistical assumptions. Certainly, in situ surveys should be part of the analyses to complete model validation. Even in data-scarce situations, that otherwise might only have point-wise information, modelling results can be used to produce comprehensive maps. These can support the spatial assessment of MPA networks and the identification of conservation hotspots (Sundblad et al. 2011, this study). Given their clarity and straightforward application, predictive maps are proposed as an important tool in spatial planning.

\section{CONCLUSIONS}

Predictive modelling can deliver maps that may support the identification of priority sites for conser- vation and spatial assessments of MPA networks. Results will be a contribution to future spatial management activities in the region, but will also assist MPA design tasks worldwide by introducing innovative methods for the application of predicted fish vulnerability in support of spatial and fisheries management. Future work may be expanded to a greater range of habitats and depths, such as the entire shelf, to analyse the effects of different biotopes on marine assemblages and, most certainly, to improve the model performance of some of the studied parameters. Furthermore, predictions should be validated in situ. MPA design and adaptive management processes may use the presented approach, or similar ones, to refine the localisation of hotspots within larger areas of elevated conservation value, i.e. to define hotspots within hotspots. It is a simple and straightforward approach to identify candidate sites for MPA networks that benefit both fisheries management and biodiversity conservation.

Acknowledgements. We thank J. Fontes, T. Morato, F. Tempera, F. Cardigos and N. Serpa, who actively participated in data collection during fish surveys in the scope of the projects CLIPE (FCT - Praxis XXI/3/3.2/EMG/1957/95), MARÉ (LIFE B4-3200/98-509), MAREFISH (FCT-POCTI/BSE/ 41207/2001), OGAMP (INTERREG IIIb/MAC/4.2/A2 2001) and MARMAC (INTERREGIIIb-03/MAC/4.2/A1 2004). We thank 3 anonymous reviewers for their constructive and valuable comments and suggestions that improved the manuscript. Individual financial support for M.S. was given by the European Marie Curie Research Training Network FREESUBNET (MRTN-CT-2006-036186), the Portuguese Foundation for Science and Technology (FCT) (SFRH/ BD/66117/2009 - COMPETE) and the Regional Fund for Science (FRC) (M3.1.5/F/168/2012). IMAR-DOP/UAz is Research and Development Unit no. 531 and LARSyS-Associated Laboratory no. 9 funded by FCT-Pest/OE/EEI/ LA0009/2013 - Projecto Estratégio LA 9 (LARSyS) - 20112014, COMPETE and by the Regional Department of Science Services (DSC)/FRC. This work is a contribution to the project MoniZEC (M2.1.2/I/018/2011). Free Access of this publication paid under the project LARSyS-PEst.

\section{LITERATURE CITED}

Afonso P, Tempera F, Menezes G (2008) Population structure and habitat preferences of red porgy (Pagrus pagrus) in the Azores, central north Atlantic. Fish Res 93: 338-345

Afonso P, Fontes J, Santos RS (2011) Small marine reserves can offer long term protection to an endangered fish. Biol Conserv 144:2739-2744

> Bellido JM, Brown AM, Valavanis VD, Giráldez A, Pierce GJ, Iglesias M, Palialexis A (2008) Identifying essential fish habitat for small pelagic species in Spanish Mediterranean waters. Hydrobiologia 612:171-184

Bertoncini AA, Machado LF, Barreiros JP, Hostim-Silva M, Verani JR (2010) Rocky reef fish community structure in 
two Azorean islands (Portugal) central North Atlantic. J Mar Biol Assoc UK 90:1353-1362

> Brock VE (1954) A preliminary report on a method of estimating reef fish populations. J Wildl Manag 18:297-308

> Bustos R, Luque Á, Pajuelo JG (2009) Age estimation and growth pattern of the island grouper, Mycteroperca fusca (Serranidae) in an island population on the northwest coast of Africa. Sci Mar 73:319-328

> Campbell N, Neat F, Burns F, Kunzlik P (2011) Species richness, taxonomic diversity, and taxonomic distinctness of the deep-water demersal fish community on the Northeast Atlantic continental slope (ICES Subdivision VIa). ICES J Mar Sci 68:365-376

Cañadas A, Sagarminaga R, de Stephanis R, Urquiola E, Hammond PS (2005) Habitat preference modelling as a conservation tool: proposals for marine protected areas for cetaceans in southern Spanish waters. Aquat Conserv 15:495-521

Cayuela L, Gálvez-Bravo L, Carrascal L, de Albuquerque F (2011) Comments on Bartolino et al. (2011): limits of cumulative relative frequency distribution curves for hotspot identification. Popul Ecol 53:597-601

> Chapin FS III, Zavaleta ES, Eviner VT, Naylor RL and others (2000) Consequences of changing biodiversity. Nature 405:234-242

> Cheung WWL, Pitcher TJ, Pauly D (2005) A fuzzy logic expert system to estimate intrinsic extinction vulnerability of marine fishes to fishing. Biol Conserv 124:97-111

Cheung WWL, Watson R, Morato T, Pitcher TJ, Pauly D (2007) Intrinsic vulnerability in the global fish catch. Mar Ecol Prog Ser 333:1-12

Clarke KR, Warwick RM (1998) A taxonomic distinctness index and its statistical properties. J Appl Ecol 35: 523-531

> Claudet J, Osenberg CW, Domenici P, Badalamenti F and others (2010) Marine reserves: fish life history and ecological traits matter. Ecol Appl 20:830-839

> Costello C, Rassweiler A, Siegel D, De Leo G, Micheli F, Rosenberg A (2010) The value of spatial information in MPA network design. Proc Natl Acad Sci USA 107: 18294-18299

> Diogo HMC, Pereira JG (2013) Impact evaluation of spear fishing on fish communities in an urban area of São Miguel Island. Fish Manag Ecol 20:473-483

> Diogo H, Pereira JG (2014) Assessing the potential biological implications of recreational inshore fisheries on subtidal fish communities of Azores (north-east Atlantic Ocean) using catch and effort data. J Fish Biol 84: 952-970

Dudley N (ed) (2008) Guidelines for applying protected area management categories. IUCN, Gland

> Dulvy NK, Sadovy Y, Reynolds JD (2003) Extinction vulnerability in marine populations. Fish Fish 4:25-64

Falcón JM, Bortone SA, Brito A, Bundrick CM (1996) Structure of and relationships within and between the littoral, rock-substrate fish communities off four islands in the Canarian Archipelago. Mar Biol 125:215-231

> Friedlander AM, Parrish JD (1998) Habitat characteristics affecting fish assemblages on a Hawaiian coral reef. J Exp Mar Biol Ecol 224:1-30

> Friedlander AM, Brown EK, Jokiel PL, Smith WR, Rodgers KS (2003) Effects of habitat, wave exposure, and marine protected area status on coral reef fish assemblages in the Hawaiian archipelago. Coral Reefs 22:291-305

Froese R, Pauly D (2013) FishBase. www.fishbase.org (accessed on 13 June 2013)

Game ET, Grantham HS, Hobday AJ, Pressey RL and others (2009) Pelagic protected areas: the missing dimension in ocean conservation. Trends Ecol Evol 24:360-369

- García-Charton JA, Pérez-Ruzufa Á, Sánchez-Jerez P, Bayle-Sempere JT, Reñones O, Moreno D (2004) Multiscale spatial heterogeneity, habitat structure, and the effect of marine reserves on Western Mediterranean rocky reef fish assemblages. Mar Biol 144:161-182

> Gladstone W (2007) Requirements for marine protected areas to conserve the biodiversity of rocky reef fishes. Aquat Conserv 17:71-87

> Green AL, Fernandes L, Almany G, Abesamis R and others (2014) Designing marine reserves for fisheries management, biodiversity conservation, and climate change adaptation. Coast Manag 42:143-159

> Halpern BS, Walbridge S, Selkoe KA, Kappel CV and others (2008) A global map of human impact on marine ecosystems. Science 319:948-952

Harmelin-Vivien ML, Harmelin JG, Almeida AJ (2001) Structure of fish assemblages on coastal rocky shores of the Azores. Bol Mus Munic Funchal 6:127-138

- Henriques S, Pais MP, Costa MJ, Cabral HN (2013) Seasonal variability of rocky reef fish assemblages: detecting functional and structural changes due to fishing effects. J Sea Res 79:50-59

IUCN (International Union for Conservation of Nature) (2013) IUCN Red List of threatened species. Version 2013.1. Available at www.iucnredlist.org (accessed 03 October 2013)

Jenks GF, Caspall FC (1971) Error in choroplethic maps: definition, measurement, reduction. Ann Assoc Am Geogr 61:217-244

Krajewski JP, Floeter SR (2011) Reef fish community structure of the Fernando de Noronha Archipelago (Equatorial Western Atlantic): the influence of exposure and benthic composition. Environ Biol Fishes 92:25-40

Kulbicki M, Cornuet N, Vigliola L, Wantiez L, Moutham G, Chabanet $P$ (2010) Counting coral reef fishes: interaction between fish life-history traits and transect design. J Exp Mar Biol Ecol 387:15-23

Lloret J, Zaragoza N, Caballero D, Font T, Casadevall M, Riera V (2008) Spearfishing pressure on fish communities in rocky coastal habitats in a Mediterranean marine protected area. Fish Res 94:84-91

> Madin EM, Gaines SD, Madin JS, Warner RR (2010) Fishing indirectly structures macroalgal assemblages by altering herbivore behavior. Am Nat 176:785-801

Magurran AE (2004) Measuring biological diversity. Blackwell Publishing, Oxford

> McCook LJ, Ayling T, Cappo M, Choat JH and others (2010) Adaptive management of the Great Barrier Reef: a globally significant demonstration of the benefits of networks of marine reserves. Proc Natl Acad Sci USA 107: 18278-18285

> Menezes GM, Sigler MF, Silva HM, Pinho MR (2006) Structure and zonation of demersal fish assemblages off the Azores Archipelago (mid-Atlantic). Mar Ecol Prog Ser 324:241-260

Morato T, Guénette S, Pitcher T (2001) Fisheries of the Azores, 1982-1999. In: Zeller D, Watson R, Pitcher T, Pauly D (eds) Fisheries impacts on north Atlantic ecosystems: catch, effort and national/regional data sets. Fisheries Centre Research Reports 9. University of British Columbia, Vancouver, p 214-220 
Myers N, Mittermeier RA, Mittermeier CG, da Fonseca GAB, Kent J (2000) Biodiversity hotspots for conservation priorities. Nature 403:853-858

- Nagendra H (2002) Opposite trends in response for the Shannon and Simpson indices of landscape diversity. Appl Geogr 22:175-186

Nash RDM, Santos RS, Geffen AJ, Hughes G, Ellis TR (1993) Diel variability in catch rate of juvenile flatfish on two small nursery grounds (Port Erin Bay, Isle of Man and Porto Pim Bay, Faial, Azores). J Fish Biol 44:35-45

Oksanen J, Blanchet FG, Kindt R, Legendre P and others (2012) Vegan: community ecology package. R package version 2.0-5. R Foundation for Statistical Computing, Vienna

Palumbi SR, Sandifer PA, Allan JD, Beck MW and others (2009) Managing for ocean biodiversity to sustain marine ecosystem services. Front Ecol Environ 7:204-211

Pauly D, Watson R, Alder J (2005) Global trends in world fisheries: impacts on marine ecosystems and food security. Philos Trans R Soc Lond B Biol Sci 360:5-12

Pittman SJ, Christensen JD, Caldow C, Menza C, Monaco ME (2007) Predictive mapping of fish species richness across shallow-water seascapes in the Caribbean. Ecol Model 204:9-21

R Development Core Team (2012) R: a language and environment for statistical computing. R Foundation for Statistical Computing, Vienna. www.R-project.org/

> Ressurreição A, Gibbons J, Kaiser M, Dentinho TP and others (2012) Different cultures, different values: the role of cultural variation in public's willingness to pay for marine species conservation. Biol Conserv 145:148-159

Reynolds JD, Dulvy NK, Goodwin NB, Hutchings JA (2005) Biology of extinction risk in marine fishes. Proc R Soc Lond B Biol Sci 272:2337-2344

Ribeiro C, Almeida AJ, Araújo R, Biscoito M, Freitas M (2005) Fish assemblages of Cais do Carvão Bay (Madeira Island) determined by the visual census technique. J Fish Biol 67:1568-1584

Rice J, Moksness E, Attwood C, Brown SK and others (2012) The role of MPAs in reconciling fisheries management with conservation of biological diversity. Ocean Coast Manag 69:217-230

Roberts CM, Branch G, Bustamante RH, Castilla JC and others (2003) Application of ecological criteria in selecting marine reserves and developing reserve networks. Ecol Appl 13:215-228

Sala E, Knowlton N (2006) Global marine biodiversity trends. Annu Rev Environ Resour 31:93-122

Santora JA, Veit RR (2013) Spatio-temporal persistence of top predator hotspots near the Antarctic Peninsula. Mar Ecol Prog Ser 487:287-304

Santos RS, Hawkins S, Monteiro LR, Alves M, Isidro EJ (1995) Marine research, resources and conservation in the Azores. Aquat Conserv 5:311-354

Schmiing M, Afonso P, Tempera F, Santos RS (2013) Predic-

Editorial responsibility: Jake Rice,

Ottawa, Ontario, Canada tive habitat modelling of reef fishes with contrasting trophic ecologies. Mar Ecol Prog Ser 474:201-216

Shannon CE, Weaver W (1949) The mathematical theory of communication. University of Illinois Press, Urbana, IL

Simpson EH (1949) Measurement of diversity. Nature 163: 688

Stachowicz JJ, Bruno JF, Duffy JE (2007) Understanding the effects of marine biodiversity on communities and ecosystems. Annu Rev Ecol Syst 38:739-766

Staples DJ, Hermes R (2012) Marine biodiversity and resource management - What is the link? Aquat Ecosyst Health Manag 15:245-252

Sundblad G, Bergström U, Sandström A (2011) Ecological coherence of marine protected area networks: a spatial assessment using species distribution models. J Appl Ecol 48:112-120

Tempera F (2008) Benthic habitats of the extended Faial Island shelf and their relationship to geologic, oceanographic and infralittoral biologic features. PhD dissertation, University of St. Andrews

Tempera F, MacKenzie M, Bashmachnikov I, Puotinen ML, Santos RS, Bates R (2012) Predictive modeling of dominant macroalgae abundance on temperate island shelves (Azores, Northeast Atlantic). In: Harris PT, Baker E (eds) Seafloor geomorphology as benthic habitat: GeoHAB Atlas of seafloor geomorphic features and benthic habitat. Elsevier, London, p 169-182

> Warwick RM, Clarke KR (1995) New 'biodiversity' measures reveal a decrease in taxonomic distinctness with increasing stress. Mar Ecol Prog Ser 129:301-305

Wood SN (2006) Generalized additive models: an introduction with R. Chapman \& Hall/CRC, London

$>$ Wood SN, Augustin NH (2002) GAMs with integrated model selection using penalized regression splines and applications to environmental modelling. Ecol Model 157: $157-177$

World Parks Congress (2003) Recommendation V.22: building a global system of marine and coastal protected area networks. 5th IUCN World Parks Congress. IUCN, 8-17 September 2003, Durban, South Africa

Worm B, Barbier EB, Beaumont N, Duffy JE and others (2006) Impacts of biodiversity loss on ocean ecosystem services. Science 314:787-790

Worm B, Hilborn R, Baum JK, Branch TA and others (2009) Rebuilding global fisheries. Science 325:578-585

Young B, Byers E, Gravuer K, Hammerson G, Redder A (2010) Guidelines for using the NatureServe climate change vulnerability index. NatureServe, Arlington, VA

Zintzen V, Anderson MJ, Roberts CD, Harvey ES, Stewart AL, Struthers CD (2012) Diversity and composition of demersal fishes along a depth gradient assessed by baited remote underwater stereo-video. PLoS ONE 7: e48522

Zuur AF, Ieno EN, Smith GM (2007) Analysing ecological data. Springer, New York, NY

Submitted: November 21, 2013; Accepted: June 20, 2014

Proofs received from author(s): September 23, 2014 